\title{
Toplumumuzda Sünnet Cerrahi Bir Operasyon Olarak Kabul Ediliyor mu?
}

\section{Does Circumcision Accepted as a Surgical Operation in Our Society?}

\author{
Tülin ÖZTAȘ 1 (D), Muhammet ASENA 2 [C
}

\begin{abstract}
1 Sağılı Bilimleri Üniversitesi Gaziyaşargil Eğitim ve Araştırma Hastanesi, Çocuk Cerrahisi Anabilimdalı. Diyarbakır/Türkiye. 2 Sağlık Bilimleri Üniversitesi Gaziyaşargil Eğitim ve Araştırma Hastanesi, Çocuk Sağlığı ve Hastalıkları Anabilimdalı. Diyarbakır/Türkiye
\end{abstract}

Öz.

Amaç: Sünnet, doğru zamanda, doğru yerde ve hekimler tarafından yapılması gereken cerrahi bir işlemdir. Çalışmanın amacı ailelerin sünnet konusundaki yaklaşımını ve bilgi düzeyini değerlendirmektir. Materyal ve Metod: Bu çalışma erkek çocuğu olan 498 ebeveyn ile gerçekleştirildi. Çalışma ailelerin sünnet konusundaki yaklaşımlarını ve bilgi düzeyini değerlendiren iki bölümden oluşan anket şeklinde yapıldı. Bulgular: Katılımcıların \%75’i inançları gereği sünnetin zorunlu olduğunu düşünüyordu. Ailelerin \%74'ü sünnetin idrar yolu infeksiyonuna karşı koruyucu olduğunu düşündüğünü belirtti. Katılımcıların \%60`ı sünnetin basit bir işlem olduğunu, herhangi bir komplikasyonu olmadığını düşünüyordu. Ailelerin \%60'ı anne-baba'nın sünnet karar verdiğini belirtti. Çalışmaya katılan ailelerin $\% 33,6$ 'sı yeni doğan döneminde sünnet yaptırdığını ifade etti. Katılımcıların \%80,8'i hastanede sünnet yaptırdığını belirtti. Katııımcıların \% 75 'i daha hijyenik koşullarda yapıldığı için hastanede sünnet yaptırdığını belirtti. Ailelerin \%17'si kadın doktora sünnet yaptırmak istemediğini bildirdi. Katılımcıların \%25'inin sünnet ile ilgili sağlık çalışanlarından bilgi aldığını ve ailelerin \%77'si bilgilendirme sonrası sünnet ile ilgili kararının değişebileceğini belirtti.

Sonuç: Çalışmamızda ailelerin azımsanmayacak oranda sünnetin faydaları ve komplikasyonlarının farkında olmadığı, sünneti cerrahi işlem olarak kabul etmediği sonucuna varılmışıı.

Anahtar Kelimeler: Sünnet, Çocuk, İnanç, Fayda, Komplikasyon.

\section{Abstract}

Background: Circumcision is a surgical procedure that must be done at the right time, in the right place and by the doctors. Aim of this study is to evaluate the approach and the knowledge of the families towards circumcision. Materials and Methods: This study is conducted with 498 families with male children. Study is conducted as a survey that is composed of two section, which evaluated the approach and knowledge of the families towards circumcision.

Results: $\% 75$ of the attendees was thinking that circumcision is an obligation of their belief. $\% 74$ of the families were thinking that circumcision is protective against urinary tract infection, $\% 60$ of the attendees were thinking that circumcision is a simple procedure that has no complication. Furthermore, $\% 60$ of the families had either of the parents as authority for decision. \% 33,6 of the families attended to the study pointed out that they performed the procedure at newborn era. $\% 80,8$ of the attendees stated that they prefer hospital as procedure place. $\% 75$ of the families that prefer the hospital as operation place stated that they choose hospital because of hygiene. $17 \%$ of the families reported that they did not want to have a female doctor circumcised. $\% 25$ of the attendees stated that they took information from medical personnel and $\% 77$ of these families that their opinions about the procedure might change after briefing.

Conclusions: Findings of the study conclude that a significant level of the families do not consider circumcision as a surgical operation, as well as they are not aware of the benefits and complications of the circumcision.

Key words: Circumcision, Children, Belief, Benefit, Complication.

\section{Sorumlu Yazar I \\ Corresponding Author}

Dr. Tülin ÖZTAŞ

Sağ|lk Bilimleri Üniversitesi

Gaziyaşargil Eğitim ve Araştırma

Hastanesi, Çocuk Cerrahi

Anabilimdalı.

Diyarbakır/Türkiye

Telefon no:05062358573

Fax:0412 2510060

e mail: tulinoztas@hotmail.com

Geliş tarihi / Received: 06.11.2019

Kabul tarihi / Accepted: 21.02.2020

DOI: 10.35440/hutfd.643666 


\section{Giriş}

Sünnet doğru zamanda, doğru yerde ve hekimler tarafından yapılması gereken cerrahi bir işlemdir. Tüm cerrahi işlemlerde olduğu gibi sünnet sonrası da çeşitli komplikasyonlar görülebilir (1). Eğitimi olmayan insanlar tarafından sünnet yapılması komplikasyon oranını artırmaktadır. Sünnetin yapılma yaşı sünnet sonrası kaygı, davranış bozuklukları gibi istenmeyen durumların gelişmesinde rol oynamaktadır (2). Genellikle inanç ve geleneksel nedenlerle yapılsa da sünnetin idrar yolu infeksiyonunu, penis kanserini ve cinsel yolla bulaşan hastalıkları önlediği bilinmektedir (3). Çalışmanın amacı ailelerin sünnet konusundaki yaklaşımını ve bilgi düzeyini değerlendirmektir.

\section{Materyal ve Metod}

Çalışma Eylül-Ekim 2019 tarihinde hastanemiz çocuk cerrahisi ve çocuk polikliniğine başvuran erkek çocuğu olan ebeveynler ile gerçekleştirildi. Bu çalışma Sağlık Bilimleri Üniversitesi Klinik Araşırmalar Etik Kurulu tarafından onaylandı (27.09.2019/ no:335).

Ailelerin sünnet konusundaki yaklaşımlarını ve bilgi düzeyini değerlendirmek için anket formu oluşturuldu. Form iki bölüm olarak düzenlendi. İlk bölümde sünnetin faydalı olup olmadığı, sünnet yapılma nedeni, faydası, risklerinin neler olduğu, ailelerin sünneti ile ilgili sağlık personelinden bilgi almak isteyip istemedikleri sorgulandı. İkinci bölümde ailelerin eğitim düzeyi, ailede sünnet kararını kimin verdiği, hangi yaşta ve nerede sünnet yaptırmayı tercih ettiği, hastanede sünnet yaptırma nedenleri, sünneti yapanın kadın veya erkek olmasının önemli olup olmadığı, sağlık personelinden bilgi alınıp alınmadığı, sağlık personeli ile görüşmenin sünnet kararını değiştirip değiş̧tirmediği soruldu. Anket sonuçları araştırmayı yapan hekimler tarafından değerlendirildi.

\section{Bulgular}

Çalışmaya 0-7 yaş aralığında erkek çocuğu olan 600 aile davet edildi. Ailelerin 550'si anket formunu doldurdu ancak formların 52'sinde veri eksikliği olduğu için çalışmaya dahil edilmedi. Toplam 498 anket formu değerlendirildi. Anket soruları ve yanıtları tablo şeklinde sunuldu (Tablo 1).

Katılımcıların \%50'si sünnetin faydalı olduğunu düşünürken, \%75'i inançları gereği zorunlu olduğunu düşünüyordu. Ailelerin \%74'ü sünnetin idrar yolu infeksiyonuna karşı koruyucu olduğunu, \%20'si idrar yapmayı kolaylaştırdığını, \%3'ü penis kanserine ve \%3'ü cinsel yolla bulaşan hastalıklara karşı koruyucu olduğunu düşündüğünü belirtti. Sünnet yaptırma nedenleri sorgulandığında çalışmaya katılan ailelerin $\% 77,7$ 'si inançlarından dolayı, $\% 17,5^{\circ i}$ enfeksiyona karşı koruyucu olduğu için, \%4,8'i çocuğu idrar yapmada zorlandığı için sünnet yaptırdığını belirtti. Katılımcıların \%88,4'ü sünnetin faydası ve riskleri ile ilgili sağlık personelinden bilgi almak istediğini belirtti. Çalışmaya katılan ailelerin \%60' sünnetin basit bir işlem olduğunu, herhangi bir komplikasyonu olmadığını düşünüyordu.

Çalışmaya katılan annelerin \%5,4'ünün okuma yazması yoktu, \%73'ü ilkokul, \%6,8'i ortaokul, \%11,8'si lise, \%3'ü üniversite mezunuydu. Babaların \%2'sinin okuma yazması yoktu, \%72,2'si ilkokul, \%3,8'sı ortaokul, \%17,4'ü lise, $\% 4,6$ 's üniversite mezunuydu.

Tablo 1. Ailelerin sünnet yaklaşımını ve bilgi düzeyini belirmek için anket soruları ve cevapları

\begin{tabular}{|c|c|}
\hline No Anket sorusu & Aile sayı (\%) \\
\hline \multicolumn{2}{|l|}{ 1. Sünnet gerekli mi? } \\
\hline Evet & $374(75)$ \\
\hline Hayır & $124(25)$ \\
\hline \multicolumn{2}{|l|}{ 2. Sünnet faydalı mı? } \\
\hline Evet & $249(50)$ \\
\hline Hayır & $249(50)$ \\
\hline \multicolumn{2}{|l|}{ 3. Sünnet yaptırma nedenleri? } \\
\hline İnanç & $386(77,7)$ \\
\hline İdrar yolu enfeksiyonuna karşı koruma & $88(17,5)$ \\
\hline İdrar yapmada zorlanma & $24(4.8)$ \\
\hline \multicolumn{2}{|l|}{ 4. Sünnetin faydaları nelerdir? } \\
\hline İdrar yolu enfeksiyonuna karşı koruma & $364(74)$ \\
\hline İdrar yapmayı kolaylaştırma & $104(20)$ \\
\hline Cinsel yolla bulaşan hastalıkları önleme & $15(3)$ \\
\hline Penis kanserini önleme & $15(3)$ \\
\hline \multicolumn{2}{|c|}{ 5. Sünnetin komplikasyonu var mıdır? } \\
\hline Evet & $199(40)$ \\
\hline Hayır & $299(60)$ \\
\hline \multicolumn{2}{|c|}{ 6. Sağlık çalışanından bilgi almak istermisiniz? } \\
\hline Evet & $439(88)$ \\
\hline Hayır & $59(12)$ \\
\hline \multicolumn{2}{|l|}{ 7. Anne eğitim düzeyi } \\
\hline Okuma yazma yok & $27(5.4)$ \\
\hline İlkokul & $364(73)$ \\
\hline Otaokul & $34(6.8)$ \\
\hline Lise & $58(11.8)$ \\
\hline Üniversite & $15(3)$ \\
\hline \multicolumn{2}{|l|}{ 8. Baba eğitim düzeyi } \\
\hline Okuma yazma yok & $10(2)$ \\
\hline İlkokul & $359(72.2)$ \\
\hline Otaokul & $19(3.8)$ \\
\hline Lise & $87(17.4)$ \\
\hline Üniversite & $23(4.6)$ \\
\hline \multicolumn{2}{|l|}{ 9. Sünnet kararını veren kimdir? } \\
\hline Anne - baba & $299(60)$ \\
\hline Baba & $115(23)$ \\
\hline Dede-nine & $84(17)$ \\
\hline \multicolumn{2}{|l|}{ 10. Sünnet yaptırma yaşı? } \\
\hline 0-1 Ay & $168(33.7)$ \\
\hline $1-12$ ay & $253(50.8)$ \\
\hline $3-6$ yaş & $77(15.5)$ \\
\hline \multicolumn{2}{|c|}{ 11. Sünnet nerde yaptırmayı tercih edersiniz } \\
\hline Hastane & $402(80.8)$ \\
\hline Sağlık kabini & $60(12)$ \\
\hline Ev & $36(7.2)$ \\
\hline \multicolumn{2}{|c|}{ 12. Hastanede sünnet yapılma nedenleri } \\
\hline Hijyenik koşullar & $374(75)$ \\
\hline Çabuk iyileşme & $79(16)$ \\
\hline Peniste şekil bozukluğu & $45(9)$ \\
\hline \multicolumn{2}{|c|}{ 13. Sünneti yapanın erkek veya kadın olması önemli mi? } \\
\hline Evet & $85(17)$ \\
\hline Hayır & 413(83) \\
\hline \multicolumn{2}{|c|}{ 14. Sağlık çalışanından bilgi aldınız mı? } \\
\hline Evet & $125(25)$ \\
\hline Hayır & $373(75)$ \\
\hline \multicolumn{2}{|c|}{ 15. Sağlık çalışanından bilgi almak kararınızı etkiler mi? } \\
\hline Evet & $384(77)$ \\
\hline Hayır & $114(23)$ \\
\hline
\end{tabular}


Sünnet kararını kimin verdiği sorulduğunda ailelerin \%60'ı anne-baba, \%23'ü dede veya nine, \%17'si babanın karar verdiğini ifade etti. Çalışmaya katılan ailelerin $\% 33,6$ 'sı yeni doğan döneminde, $\% 50,8$ 'i ilk bir yıl içinde ve $\% 15,6$ 'sı okul öncesi dönemde (2-6yaş) sünnet yaptırmayı tercih ettiğini ifade etti. Katılımcıların \%80,8'i hastanede sünnet yaptırdığını, \%12'si sağlık kabininde, \%7,2'si evde sünnet yaptırdığını belirtti. Hastanede sünnet yaptırma nedenleri sorulduğunda ailelerin \%75i daha hijyenik koşullarda yapıldığını ve enfeksiyon riskinin daha az olduğunu, \%16'sı daha çabuk iyileştiği için, \%9'u peniste şekil bozukluğu olduğu için hastaneyi tercih ettiğini belirtti. Katılımcıların \%25'inin sünnet ile ilgili sağık çalışanlarından bilgi aldığı saptandı. Ailelerin \%17'si kadın doktora sünnet yaptırmak istemediğini bildirdi. Sağlık çalışanları ile görüşme sonrası ailelerin \%77'si sünnet ile ilgili kararının değişebileceğini belirtti.

\section{Tartışma}

Sünnet en sık yapılan cerrahi işlem olmasına rağmen gerekli olup olmadığı tartışma konusu olmaya devam etmektedir. Sünnetsiz çocuklarda sünnet derisi ile mukoza arasında debris veya idrar birikmesi sonucu parafimozis ve rekürren balanit geliştiği ve bu çocukların idrar yapmada güçlük çektiği belirtilmiştir. Sünnet yapılan çocuklarda bu enfeksiyonların daha az görüldüğü raporlanmıştır (4). Çalışmamızda aileler (\%4) bebeğin sünnet yaptırmadan önce idrar yapmada zorlandığını ve huzursuz olduğunu sünnet sonrası ağlamalarının azaldığını ifade etti. İlk üç ayda yapılan sünnetlerin üriner sistem enfeksiyonunu on kat azalttığı bildirilmiştir (2). Yapılan bir çalışmada antenetal tanı almış komplike üriner sistem anomalisi olan çocuklarda üriner sistem enfeksiyonunu önlemek için sünnet önerildiği belirtilmiştir $(5,6)$. Çalışmamızda da yenidoğan döneminde sünnet yaptırma nedenlerinden biri üriner sistem anomalisi olmasıydı. Sünnetin penis kanserine karşı koruyucu olduğu ve cinsel yolla bulaşan hastalıkları (HIV, HPV, HSV2) azalttığı raporlanmıștır (5-7). Çalışmamızda katııımcıların sünnetin faydaları ile ilgili yeterince bilgi sahibi olmadığı saptandı. Ailelerin bilgilendirilmesi konusunda çocuk sağlığı, çocuk cerrahisi ve üroloji uzmanlarının yanı sıra birinci basamak sağlık kuruluşunda çalışan hekimlere de büyük sorumluluklar düşmektedir.

Sünnet küçük cerrahi bir işlemdir ve potansiyel riskler taşımaktadır (5). Sünnet sonrası komplikasyon oranı yenidoğanlarda $\% 0,2$ olarak belirtilmiş ancak yaş arttıkça bu oranında arttığı ve ilk bir yaş içinde yapılan sünnetlerde $\% 0.4$ olduğu bildirilmiştir (8-10). En sık görülen komplikasyonlar kanama ve enfeksiyon olup daha az oranda sünnet derisinin az veya çok kesilmesine bağlı estetik olmayan görünüm, nadir olarak glansın amputasyonu, nekrotizan fasiit, sepsis, menenjit gibi hayatı tehdit eden komplikasyonlar bildirilmiştir (1). Çalışmamızda katılımcıların \%60'nın sünnet sonrası oluşabilecek komplikasyonlarla ilgili bilgisi yoktu. Aileler sünneti ciddi ve faydalı bir operasyon olmaktan ziyade basit, herhangi bir riski olmayan bir gelenek olarak algılamaktaydı. Ailelerin \%20'si sünnetin doktor tarafından ve hastanede yapılmasının önemli olmadığını düşünüyorlardı. Katılımcıların \%17'si ise sünnetin dini bir zorunluluk olduğunu ve erkeklerin yapması gerektiğini belirtmişti. Bu nedenle kadın doktor yerine, evde veya sağlık kabininde eğitimsiz kişilere sünnet yaptırmayı tercih etmişlerdi. Sünnet ile ilgili bilgilendirmenin sünnet kararına etkili faktörlerden biri olduğu düşünülmüştür. Binner ve ark yaptığı çalışmada sünnetin tıbbi endikasyonları, olası riskleri ile ilgili bilgilendirme öncesi ve sonrası yapılan anketlerde ailelerin bilgilendirilmesinin yenidoğan sünneti yaptırma kararına etkisinin olmadığı raporlanmışıı (11). Başka bir çalışmada ise sünnet ile ilgili bilgi verilmesinin sünnet kararında nadiren etkili olduğu raporlanmıştır (12). Bisono ve ark yaptığı çalışmada sünnet kararını sağ|lı personelinin bilgilendirmesinin etkilediği belirtilirken, Ahaghotu ve ark yaptığı çalışmada sadece $\% 20$ katılımcının doktor tavsiyesinden etkilendiği bildirilmiştir $(4,13)$. Çalışmamızda da aileler (\%77.8) sünnet ile ilgili bilgilendirilmenin kararlarını değiştireceğini belirtmişlerdir. Toplumun bilinçlendirilmesi, sünnetin cerrahi bir işlem olduğu ve yapanın cinsiyetinin önemli olmadığının anlatıması ile eğitimsiz kişilerin sünnet yapması ve dolayısıyla olası komplikasyonlar büyük oranda azaltılabilir.

Irk, etnik köken, inanç, kültür, ailesel gelenekler, sağık hizmetlerine erişim sünnet yaptırma kararında rol oynayan faktörlerdendir $(4,14)$. Sünnetin en sık penisin daha kolay temizlenmesi ve hijyen nedeniyle yapıldığı bildirilmiştir (15). Sünnet kararını vermede geleneklerin büyük rolü olduğu ve babanın sünnetli olmasının yenidoğan sünnetinin yapılmasında en önemli etken olduğu raporlanmıştır (16). Ahaghotu ve ark yaptığı çalışmada inançların sünnet kararı verilmesinde büyük bir rolü olmadığı raporlanmıştır (4). ÇaIışmamızda olduğu gibi sünnetin dini uygulamalar ve kültürel nedenlerle yapıldığı, nadiren idrar yolu enfeksiyonunu ve cinsel yolla bulaşan hastalıkları azaltmak için sünnet yapıldığı belirtilmiştir (7).

Sünnet kararını vermede annelerin babalardan daha fazla rol oynadığı raporlanmıştır (4). Adler ve ar yaptığı çalışmada ise $\% 50$ oranında anne ve baba birlikte, $\% 30$ oranında anne sünnet kararını veriyordu (17). Çalışmamızda çoğunlukla anne baba birlikte karar verdiklerini belirtmişlerdi Annenin tek başına sünnet kararı vermediği belirlendi. Bu durumun ataerkil aile yapısından kaynaklandığı düşünülebilir.

İdeal sünnet yapılma yaşı da çok tartışılan konularından biridir. Yapılan çalışmalarda daha hızlı iyileşme ve daha az komplikasyon gelişmesi nedeniyle yenidoğan döneminde sünnet yapılması önerilmektedir $(18,19)$. İki yaşından küçük çocuklarda yapılan sünnetin idrar yolu enfeksiyonuna karşı koruyucu olduğu belirtilmiştir (2). Sünnet için en uy- 
gun zamanın yenidoğan dönemi olduğu, bu dönemde yapılmazsa 7-10 yaş arasında yapılması önerilmiştir (3). 3-5 yaşında yapılan sünnetin çocuk tarafından bir saldırı olarak algılanabildiği ve çocuğun benliği üzerinde olumsuz etkilere neden olabileceği bildirilmiştir (3). Çalışmamızda daha çabuk iyileştiği, ailesel bir gelenek olduğu, üriner sistem anomalisi nedeniyle doktor önerdiği için yenidoğan döneminde sünnet yapıldığı saptandı. Illk yaşta sünnet yapılma nedeni çocuğun olayın farkında olmaması ve sünnet sonrası bakımının daha kolay olduğunu düşünülmesiydi. Okul öncesi yapılma nedeni ise ekonomik sebepler nedeniyle daha önce yapılamamış olması, sünnetin ağrılı bir işlem olduğunun düşülmesi nedeniyle ertelenmesiydi. Çalışmamızda ailelerin sünnet yaşı ve sonrası oluşabilecek psikolojik etkilenmeler hakkında bilgileri yetersizdi.

Çalışmamızda ailelerin azımsanmayacak oranda sünnetin faydaları ve komplikasyonlarııı farkında olmadığı, sünneti cerrahi işlem olarak kabul etmediği sonucuna varılmıştır. Sünnet genellikle inanç nedeniyle yaptırılsa da yapılma yaşı, faydaları, riskleri konusunda toplumun bilinçlendirilmesi sünnetin ciddi bir cerrahi operasyon olduğunun algılanmasında ve eğitimsiz kişilerin sünnet yapmasını önlemede büyük öneme sahiptir.

\section{Etik Onam: Bu çalışma için Sağlık Bilimleri Üniversitesi Kli- nik Araştırmalar Etik Kurulundan onam alınmıştır. (27.09.2019/ no:335).}

\section{Kaynaklar}

1. Bastos NJM, de Araújo JG Jr, de Almeida NMF, Passos BR, de Bessa $\mathrm{J} \mathrm{Jr}$. Fiqueiredo AA. Prospective randomized trial comparing dissection with Plastibell circumcision. Journal of Pediatric Urology 2010; 6(6):5727.

2. Kestel M, Tarhan H, Şahin H. Erkek sünneti. Muğla Sıtkı Koçman Üniversitesi Tıp dergisi. 2018;5(1):27-31.

3. Yavuz M, Demir T, Doğangün B. Sünnetin çocuk ruh sağlığı üzerine etkisi gözden geçirme çalışması. Türk Psikiyatri Dergisi. 2012; 23(1):6370.

4. Ahaghotu $\mathrm{C}$, Okafor $\mathrm{H}$, Igiehon $\mathrm{E}$, Gray E. Psychosocial factors Influence parental decision for circumcision in pediatric males of African American descent. J Natl Med Assoc. 2009;101:325-330.

5. Hutson JM. Circumcision: a surgeon's perspective. J Med Ethics 2004;30:238-240.

6. Kacker S, Frick KD, Gaydos CA, Tobian AAR. Costs and effectiveness of neonatal male circumcision. Arch Pediatr Adolesc Med. 2012;166(10):910-918.

7. Sansom SL, Prabhu VS, Hutchinson AB, An Q, Hall I, Shrestha RK et al. Cost-effectivenes of newborn circumcision in reducing lifetime HIV risk among US. Males. PLOS ONE 2010: 5 (1): e8723.

8. El Bcheraoui C, Zhang X, Cooper CS, Rose CE, Kilmarx PH, Chen RT. Rates of adverse events associated with male circumcision in U.S. medical settings, 2001 to 2010. JAMA Pediatrics. 2014; 168:625-634. 9. Srinivasan M, Hamvas C, Coplen D. Rates of Complications After Newborn Circumcision in a Well-Baby Nursery, Special Care Nursery, and Neonatal Intensive Care Unit. Clin Pediatr (Phila). 2015; 54:118591.

10. Hung YC, Chang DC, Westfal ML, Marks IH, Masiakos PT, Kelleher $\mathrm{CM}$. A longitudinal population analysıs of cumulative risks of circumcision. J Surg Res. 2019;(233):111-117.

11. Binner SL, Mastrobattista JM, Day MC, Swaim LS, Monga M. Effect of Parental Education on Decision-Making About Neonatal Circumcision. South Med J. 2002: 95(4):457-461.

12. Mitchell TM, Beal $C$. Shared decision making for routine infant circumcision a pilot study. The journal of Perinatal Education. 2015;24(3):188-200.

13. Bisono GM, Simmons L, Volk RJ, Meyer D, Quinn TC, Rosenthal SL. Attitudes and Decision Making about Neonatal Male Circumcision in a Hispanic Population in New York City. Clin Pediatr (Phila). 2012;51(10): 956-963.

14. Harris VC, Links AR, Walsh J, Lee AH, Tunkel DE, Boss EF. A systematic review of race/ethnicity and parental treatment decision-making. Clin Pediatr (Phila). 2018;57:(12): 1453-1464.

15. Xu B, Goldman H. Newborn circumcision in Victoria, Australia: reasons and parental attitudes. ANZ Journal of Surgery. 2008 ;78(11):1019-22.

16. Bossio JA, Pukall CF, Steele S. A review of the current state of the male circumcision literature. The Journal of Sexual Medicine. 2014;11:2847-2864.

17. Adler R, Ottaway S, Gould S. Circumcision: we have heard from the experts; now let's hear from the parents. Pediatrics 2001;107(2):E20.

18. Morris $B \mathrm{j}$, Bailis SA, Wiswell TE. Circumcision rates in the United states.Rising or falling? what effect might the new affirmative pediatric policy statement have. Mayo Clin Proc. 2014;89(5):677-686.

19. Banieghbal B. Optimal time for neonatal circumcision: an observation based study. Journal of Pediatric Urology . 2009:5;359-362. 